\title{
Comparative Analysis of the Performance Evaluation of the Human Resources in the Hotel Industry
}

Silvia ANGHEL-VLAD ${ }^{1}$

Abstract
The main reference point of the performance is the improvement of the quality
of the services offered by the manager of the hotel and the aim of the performance is to
motivate the human resources. The success of a company depends mostly on the
performance of the employees. In order to determine the individual input of each
employee, it is necessary to set the clear goals. Once the performance standards are
set, it is easier to evaluate the employees.
Taking the responsibility has an essential role to obtain the professional
performance. It is essential to avoid the underestimation or the overestimation of the
competences of the employees in order to be able to do all the necessary tasks in order
to achieve performance.
The role of the manager is to identify and to mention how achieving the goals
of the company ensures the satisfaction of the employees. The motivation of the
employees not only brings personal satisfaction but also physical satisfaction. Besides
all these, the self-respect grows a lot. Trusting their own power, the positivism will
bring you only benefits and performance.

Keywords: feedback, professional promotion, performance professional, performance evaluation, hotel industry

JEL classification: $M 120, M 12, M 52, L 83$

DOI: $10.24818 /$ RMCI.2018.2.175

\section{Introduction}

The characteristics of the professional performance of the human resources in the hotel industry implicate the motivation depending on the individual characteristics of each employee, especially in the touristic area.

The feedback provided by the managers leads to the diversity of the services offered by a person, from motivation to achieving the performance. The feedback means the level of financial or non-financial motivation which is used in order to achieve the performance target of the human resources in the hotel industry.

The main reference point of the performance is the improvement of the quality of the services offered by the manager of the hotel and the aim of the performance is to motivate the human resources. Taking the responsibility has an

${ }^{1}$ Silvia Anghel-Vlad, West University of Timisoara, E-mail: silvia.vlad@e-uvt.ro 
essential role to obtain the professional performance. It is essential to avoid the underestimation or the overestimation of the competences of the employees in order to be able to do all the necessary tasks in order to achieve performance.

\section{Literature review}

We are motivated when we talk about the performances, we set clear objectives that we want to achieve. We have a bigger self respect when we are appreciated by the persons we work with or for and this is a good enough reason to wish to achieve the best performances.

Does the prior set of the objectives help to achieve performance? The simple answer is YES. The value of setting a precise goal makes the people think about the future when talking about the goal achieving, and this expectation makes them achieve the desired performance.

The negative aspect of the prior setting of the goals is the fact that if you have a goal that is impossible to be achieved, you can be frustrated, which leads to non-performance. Here it comes the motivation which has an essential role in achieving the performance.

The employees need self-accomplishment by achieving performance at work, and all these can be achieved with persistence and a lot of work, and also with the acknowledgement of their results by the managers. The needs hierarchy done by Abraham Maslow (see figure 1) is efficient to understand the selfaccomplishment process of each individual, showing the order for the priorities of the human resources.

Self actualization

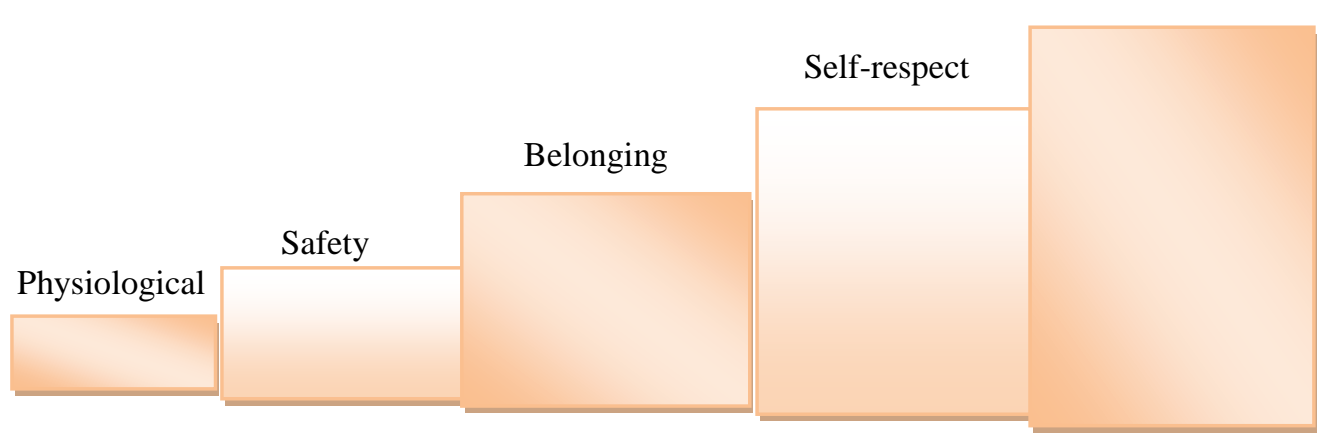

Figure 1. Hierarchy of human needs

Source: Managing Human resources, Sherman, Bohnlander, Chruden

When the concept of hierarchy of needs is applied to develop the company, the involvement of the manager is obvious. The managers have the responsibility, according to figure 1 . to create a proper environment where the employees can develop (Arthur W. Sherman, Jr., George W. Bohlander şi Herbert J. Chruden, 1998, p. 295). A well organized system allows the employees to keep the gained performances and, moreover, to improve them and to be motivated according to the „pay for performance” system (John J. Gabarro, 1991, pp. 483-484, S.U.A).

176 Review of International Comparative Management

Volume 19, Issue 2, May 2018 
The most important characteristic of the „pay for performance” system is the aggregation level through which the performance is defined as ,individual, group and organisation-wide" (Edward E. Lawler, 1981, p. 82-85), which is assigned to the employees by the manager. The management team of the hotel needs to find the most appropriate employees, a successful team that will bring the desired performances to the hotel and to them.

A successful team is a way to performance. The main purpose is to implement ideas that will lead the employees to the performance road, having in mind the fact that each team member has their own goal.

Once the reason for which you choose a certain way is discovered, it will be easier to achieve performance. In order to achieve the personal satisfaction, you need to have continuity and to set clear goals. With a positive attitude, much work and continuity, the positive results will appear. The well set of goals always bring with them the successful stories, you only have to be confident and aware of the change you bring into your life and the performance you want to achieve.

The study conducted by R. L. Lynch and K. F. Cross allows us to bring the performance slowly in the touristic area as ,un insieme di processi per determinare concordentemente l'obiettivo che si deve raggiungere e i sistemi per il sviluppo del personale in modo di raggiungimento del performance" (Stefano Paneforte, p. 215, M. Armstrong, op.cit, 1999). This quote confirms what we have written in the previous paragraph about the set of the goal in order to achieve performance. The role and the expectations of the individual need to be set at the moment the goals are set. Following, the stages need to be followed so that the attention is focused on their own professional development.

According to many writers, it is noticed that a handling of the performances based on competences is able to appraise the behavior which is the goal of the performance.

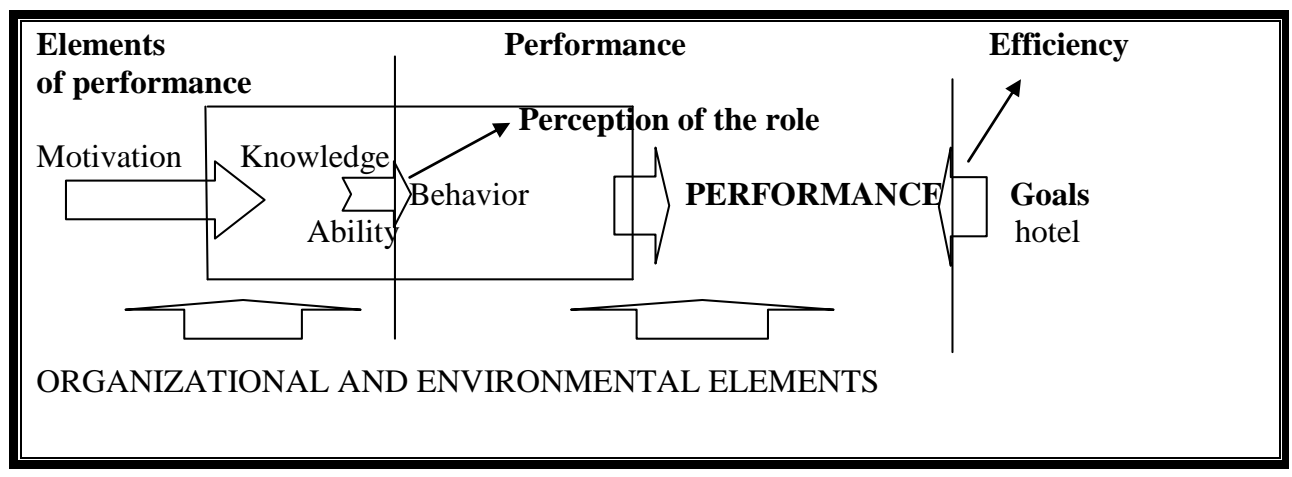

Figure 2. Performance process

Source: Stefano Panoforte, La gestione delle persone

The process of performance is described in figure 2 in order to understand how the contribution of each person can achieve efficiency. We can notice in figure 
2 that everything starts from the motivation of each individual regarding the perception of their role in the company in order to achieve the performance required by the management. In this process, the organizational and environmental elements have a role in the entire perception regarding the efficiency. The performance needs to be used depending on the behavior.

The success of a company depends mostly on the performance of the employees. In order to determine the individual input of each employee, it is necessary to set the clear goals. Once the performance standards are set, it is easier to evaluate the employees. In other words, motivation has an essential role in setting the goals of the human resources in the hotels. The more the management use the most suitable methods to satisfy the employees, the more their performances will reach a higher level of development.

Motivation is one of the responsibilities of the management; they have to find the best methods so that the employees may achieve the performance at work. One important thing in the organization, which most of the times is not highlighted enough, is that the employee by himself is able to motivate himself because the motivational processes are triggered and coordinated from the inside. The role of the manager is to identify and to mention how achieving the goals of the company ensures the satisfaction of the employees. The motivation of the employees not only brings personal satisfaction but also physical satisfaction. Besides all these, the self respect grows a lot. Trusting their own power, the positivism will bring you only benefits and performance.

Based on the research conducted with the purpose of discovering the characteristics of work in hotel industry, I made the comparative analysis of the performances of the employees $n$ the hotel industry. So I used a questionnaire that I applied on the two analyzed hotels.

In order to understand which the reason to achieve performance is, I conducted a survey to prove the efficiency of the methods used in the analyzed hotels. The questionnaire applied to the employees of the hotels had a very important role in the evaluation of the performances of the employees and in the discovering of the complaints and of the satisfactions, the relationships at work, providing the necessary information to the employees, the level of the salaries, all these presented next in this article.

Promotion requires a lot of efforts and performance at work. For the company, the promotion ensures the quality of the services offered by the employee, the employees are evaluated in order to determine if they invested enough efforts in order to receive the promotion, the difficulties of the new job and, especially the responsibility they need to prove. Just not to fail this promotion process, a conference is organized where all the directors of the hotel are called in and they decide if the employee will be promoted or not, depending on the performances. In the promotion process, more criteria are taken into account and the employee has to fulfill all the criteria in order to be promoted. All these conditions are mentioned in table 1 . Here we can notice the main characteristics the employee needs in order to be promoted and the way the employee can be

178 Review of International Comparative Management

Volume 19, Issue 2, May 2018 
motivated to have results and the analysis (Encyclopedia of Management, Employee Job Evaluation, p. 253).

Table 1. Motivation elements

\begin{tabular}{|l|l|}
\hline Motivation elements & Analysis criteria \\
\hline Skills-competences & $\begin{array}{l}\text { Education } \\
\text { Experience } \\
\text { Knowledge }\end{array}$ \\
\hline Efforts & $\begin{array}{l}\text { Physical effort } \\
\text { Psychical effort }\end{array}$ \\
\hline Responsibility & $\begin{array}{l}\text { Decision } \\
\text { Judge } \\
\text { Business internal contracts } \\
\text { Responsibility for personal actions and for } \\
\text { equipments, financial responsibility, e.g. for } \\
\text { confidential information }\end{array}$ \\
\hline Working conditions & $\begin{array}{l}\text { Assumed risks } \\
\text { Comfort }\end{array}$ \\
\hline
\end{tabular}

Source: Encyclopedia of Management, Employee Job Evaluation

At Courtyard Marriott hotel the promotion has some reference points as goals, which are precisely defined by the manager and refer to the experience gathered previously, the training level and also the efforts at work. Without this extremely important element, the employee will not take into account in the promotion process. The interesting part of this study about the promotion is the way the employee is promoted. He involves himself in the discussion with the manager of the hotel and expresses his point of view regarding the performances. There is an informal discussion when the employee is informed about a possible promotion, depending on the reasons the employee brings.

So everything depends on the performances the employee gathered during the services offered in the Courtyard Marriott hotel, his relationship with his colleagues, the impression he created for the managers. It is about self-values, which give you the opportunity to express your own beliefs regarding the promotion. To bear in mind that the employees are their own evaluators and the managers express their own opinion regarding the promotion. This is why the employee needs to show his qualities for a possible promotion. If not, he will lose a precious promotion opportunity that the manager might have taken into account.

The person who wants to promote has to express clearly the changes he wants. This behavior can be obtained through the responsibility to assume the point of view, the self confidence regarding the position you want to get. This has to be clear in order for the management to understand the demands of each employee.

When a negative answer is received from the management, the employee has to express his point of view, to support his position and to become proud of him in the discussion, no matter of the result. Moreover, he should try again to get the promotion. This behavior will give him the performance on long term, he will 
try again to promote, promotion desired since long ago, and he will get it with a lot of perseverance and work.

This method is used in the analysis of the promotion in order to help the employees in the hotel to set the long term goals regarding the development and promotion. This process of self-evaluation includes the four stages the employee has to take into account at the moment of the informal interview with the manager. The four stages refer to his own interests, the development level that needs to be the same as the manager's expectations for the opened job, the performances the employee wants to achieve and the way he will action to get them. In order to promote the employees, the manager of the IQ hotel uses the CAP process „Competency Acquisition Process" (Jason D. Shaw, Nina Gupta, and John. E. Delery, 2002, p. 23) based on the following elements: recognition, understanding, value, feedback and involvement in the job that is promoted.

Through this process, the employee has to simulate some situations that he will possibly have to face in case of a promotion. This way the abilities to work in stress conditions, such as the way he will pass over the obstacles are tested. If he passes the test, the employee will be promoted.

\section{Findings}

According to Lukacs Edit, (2002), „the evaluation of performances is the process of setting the way the employee does his tasks and responsibilities according to the job description, comparing to the set standards and the communication of the results to the employees". The evaluation of the performances is a base activity of the human resources management and takes place with the purpose of establishing the way the employees in a company do their tasks and their responsibilities, which has a direct impact on the performance of the hotel.

Performance evaluation in a process through which it is decided how good an activity is done by the employees in a hotel and not only. Human resources evaluation has three different activities: behavior evaluation, the capability and the ability to grow and the achieved performances. To have and to use a performance evaluation system has a positive effect upon: the employee selection system, the employees improvement using training programs, motivation (awards, promotions) and also to distribute the employees to other departments (transfers, dismissal).

In order to create a correct and effective evaluation system only the reliable information related to the professional behavior will be used. The evaluation criteria are developed using the job analysis, and the performance standards have to be sent to the employees in written. In order to have a good result, the capacity to get identical results repetitively is used.

Each individual has different expectations regarding the evaluation of the performances. The employees want to be motivated for their performance, and this is why they have expectations regarding the admission of these performances because it helps them to find out more about themselves. "Self-development 
requires opens to feedback and receptiveness to alternative approaches to the job" (John J. Gabarro, 1992, p.199) which emphasizes the fact that the employees need the managers to admit their competences. The secret of motivation is to improve the knowledge and the performance at work. Each individual has their own motivations, which differentiate them from the others. "Il motore che spinge le persone a agire e la motivazione" (Antonio Carretta, Murray M. Dalziel e Alain Mitrani, 2004, p. 148).

A high self-respect has a positive impact regarding the admission of the results from the managers. It is basically to have respect and communication between the team members in order to get to performance. The respect is a basic element of quality of the services that we offer and we receive.

A person who has a low self-respect, tends to protect himself from future failures, which usually tend to become minimum expectations regarding the performance, a lower creativity that blocks the innovative ideas and the desire to explore. Moreover, "chi ha una bassa considerazione di se stesso non vuole rischiare" (Diana Cawood, 1988, p.38), they remain limited to the same job and have no intention to promote; they do all that the others decide from them.

\section{Rome, Italy}

The results regarding the performance in Courtyard Marriott Hotel in

The gained results in the Courtyard Marriott hotel in Rome are high because the employees are on the first place no matter what happens, meaning that the employees are motivated to achieve these performances. The manager always asks the questions: „How good I want this thing to be done?”, „How good this task needs to be done by the employee?", these are questions that are usually asked by the manager who expect the employees to perform.

The process of performance evaluation is the multitude of standardized procedures used to gather information regarding the professional behavior of the employees. Courtyard Marriott hotel guides itself using the principle of Michelangelo „The perfection is made by details "because the managers want the employees to go further than what the others do, to achieve performance using their own experience. In order to achieve a high level of performance, the hotel invests a lot of money in trainings and in exchange of experience in other countries with the Lean Sigma Approach professional development system.

Lean Sigma Approach aims to develop the human resources and it is a very strong competitive process, an innovative one through the need to develop the abilities of the employees. Lean Sigma Production system means the development of the human resources in order to have a total quality of the services offered by the employee. It is based on the respect for the employees, team work and the desire of each employee to perform. The purpose of the evaluation of the performances is: to express and to measure correctly the goals, to set the next steps and the way the employees can develop professionally and to increase their performance, to establish the deviations for the goals and to change and minimize the risks in case of promoting or keeping the some incompetent employees. 
The evaluation of performances in Courtyard Marriott hotel is based on the character traits and the behavior, the physical and intellectual traits, general and specific performances, the potential of professional development. The performance criteria aim at either the results, either the past events or the future capability. Among these ones, we mention: personal characteristics (aptitudes, behavior and personality), ability, professional characteristics (attention, availability, selfcontrol), the interest for the resources allocated to the position, the orientation for excellence, concern for the general interest of the company, job adaptability, ability to take decisions and the ability for innovation, team spirit, delegation of responsibilities and training for the employees, communication etc.

Thanks to the fact that the manager is always available for the employees and helps them to set their goals, he helps them to achieve the goals they had previously set. One thing is sure, in order to do the changes the employees want, it is necessary to focus on these essential aspects: goals, expectations, context, action and continuous learning. This is why the managers of the Courtyard Marriott hotel use the training to improve the performances but they do not focus only on the improvement of the performance but also on the quality of the services offered by the employee.

The results regarding the performance are significant, the employees as motivated in order to achieve them, they are stimulated to do more for themselves, through the training. The simple fact that the employees are motivated to improve their intellectual abilities permanently has a positive effect. The result is the selfsatisfaction, the professional self-accomplishment. The manager of the hotel focuses on the needs of the employees; he started to realize how important the selfrespect and the admission of the results of each employee are. The self-respect is the line that guides the professional performance and the manager of the Courtyard Marriott hotel improves it through the trust in the human resources he coordinates.

On the other side, the Courtyard Marriott system has great expectations regarding the employees, but at the same time they offer the employees the possibility to perform. Through the admission of the results, the employees become more responsible for their actions and they manage to make the most of the effort they invest in order to achieve performance. The discipline at Courtyard Marriott hotel makes the employees to be completely involved in the decision taking regarding the expectations they have from themselves and from the management team. This plan is used to enlarge the possibility of each employee to set well defined and precise goals regarding the performance. The management of the company wants qualified employees, and this is why they help them to achieve performance at Courtyard Marriott hotel.

\section{The results in IQ Hotel in Timisoara, Romania}

In IQ hotel in Timisoara they aim to motivate the employees to improve their performance. Being smaller than Courtyard Marriott hotel, the manager of the IQ hotel focuses on creating a team in order to achieve performance. Each team member has well set goals, according to the needs of the company and to the needs of the employees in order to achieve the highest level of performance. The role of 
the manager is quite simple at first sight, he has to do something so the employees achieve performance through work. This is very difficult to do because sometimes the improvement of the performances of the employees needs time and much money.

On the one side IQ hotel invest in people, in their performance, the employees go to different trainings that give them the opportunity to improve their professional knowledge. The logic of the manager is to have professional results after they gain experience, and these results to come from the services offered to the customers of the hotel. Its logic is „our customer, our master namely the satisfactions of the needs of the customers is above everything.

To conclude, I can say that the performance of the employees is obvious if the employees are motivated accordingly, and the motivation can be financial or personal. The employees that are appreciated by the managers of the hotel will always find a way to work in the company for a long period of time; they will be motivated to achieve performance for themselves and for the hotel. In the hotel area, the collaboration between the employees and the manager is essential. A balance between the expectations of the managers and the employees needs to be reached, without an efficient collaboration, trust, motivation, the results cannot be obtained, no matter of the commitment of the employees.

Motivation is related to the performance process. The two stages have the main goal to develop the professional abilities that each employee has. In a large view, everything is based on the way the employee sets the goals. The other members an employee work with have an important role in the hotel industry. The moment there is no tension between the team members, there is an increased efficiency for all the team members. Through this process of training on the job together with the team spirit, the performance will appear.

Nevertheless, the training stage contains a series of procedures that the employee has to follow. It is an agreement that the employee has with himself, made to set the goals he wants to achieve, the self-control that he has during the stressful moments and last but not least, the way he manages the tiredness and the stress gathered at the job.

So, the competences during doing the daily tasks are related to the performance. The competences can refer to the motivation, personal goals and they have an impact on the behavior, leading to performance. These characteristics are found mainly at the employees who set their goals, who want to be performing, who have the desire to take responsibilities and to take risks. From the efficiency of the costs for employees' point of view, the main rule is to assume, based on the motivation and on the personal goals, the development of knowledge and the ability to improve. The evaluation of the professional performance is a tool used to improve the communication between the manager and the employee of the hotel, and it specially evaluates efficiently the results during the evaluation period. 


\section{Conclusions}

The management performance is the process of analyzing the employees' competences and also the feedback provided to them in order to improve the personal and organizational development. Measuring the performance and the feedback provided to the employees improves the performance. Moreover, the investment in the individual performance means a competent organizational performance. „Organizations have higher productivity when top management encourages supervisors to set goals, assess performance, and provide feedback to employees" (Robert Rodgers and John E. Hunter, 1991, pp. 323-336). Robert Rodgers said that the managers should encourage the employees to set goals in order to gain performance but the most important is to provide them with feedback regarding their goals. One reason for which the managers need to trust their employees is that performance is considerably improved when it is considerably analyzed and rewarded.

Through the attendance of the employees to the achieving of the goals in the hotel, they have the opportunity to be satisfied at work, which is an important aspect regarding the performance. The companies have created a system to admit the performances in order to categorize the employees depending on the achieved goals. The main goals of the „merit-based system” that Courtyard Marriott hotel uses are to encourage the employees to achieve the highest performance at the highest level. The employees who have the better results receive some marks that differentiate them from the other employees and give them the opportunity to go to the next hierarchical level.

Courtyard Marriott gives bonuses to the 300 employees depending on their performances. The human resources department of the hotel builds competitive advantages through the systematic evaluation of motivation in order to be sure that they will help the hotel achieve the targets.

Another point of interest in achieving the results regarding the performance is the fact that the managers have the main responsibility to decide how each employee will be rewarded, by making comparisons with other employees. The managers thus are flexible in their decisions and the employees are paid according to their performances. Not only that the Courtyard hotel has the trend to pay more than IQ hotel, but they also base on the difference between the competent and the incompetent employees.

The motivation system in Courtyard Marriott Hotel which means to make the managers to take decisions regarding the performances of the employees, and also the better financial motivation of the employees, has an important role in the success of the hotel. „This practices help Marriott continue to be rank as one of the best place to work". Because of the motivation of performances and the experience in the hotel, Courtyard Marriott manages to use the best strategy through encouraging the employees to make efforts and to achieve their targets so that the hotel can achieve performance. 
IQ hotel in Timisoara has another version regarding performance. Being a smaller hotel and having only 8 employees, the performance can be achieved at the group level. The personal performance is achieved at the organizational level. Because of the differences in the individual salaries, they can have conflicts. This is why the manager coordinates the employees to the team work regarding the performance improvement.

The employees achieve performance by working in teams, in a proper and conflict less environment, in order to achieve the targets. Paying some employees more that paying the others leads to performance, especially when there is a combination between the individual motivation and the activities that involve collaboration with other employees. Anyway, to motivate the employee to reach the performance brings benefits to both parties, to the manager and to the employees. In order to avoid the discrimination regarding the financial motivation, the manager gives some benefits to those who have better results.

The main point of interest of performance is the improvement of the quality of the services offered by the manager of the hotel and has as purpose to motivate the employees. The process of evaluation of the individual performances ensures the feedback provided by the superiors and has as reference points a series of professional criteria through which the performance standard is achieved. Assuming the responsibilities has an essential role for the achieving of the professional abilities. It is important to avoid undervaluation or over-evaluation of the abilities of the employees in order to be able to assume all the demands that are required for the achieving of the performances.

What is important, first of all in order to achieve performance a safe and stress less environment need to be created among the team members and the managers need to make sure that each employee achieves their targets. The team needs to focus on the strategy and the actions and not on the analysis and friendship inside the team. And mostly the conflicts at work do not have to have an impact upon the personal and private life of the team members.

A successful team is built with the members who want to make some dreams come true and they do whatever is needed to achieve this purpose. The manager of the IQ hotel aims to create this atmosphere among the employees every year and he wishes that the customers are satisfied with the quality services that this hotel provides to them for a 3 start hotel. The management of the hotel does not want to have unsatisfied employees but they also cannot continue to financially motivate them continuously. This is why they are interested in motivating them through performance and productivity. One of the most famous methods to improve the performances of the employees is to ask them what they want from their job and the managers of the hotel to help them get what they want.

Courtyard Marriott and IQ hotels respect their employees by providing them the motivation that the performance standard requires, trying to develop the professional quality of the hotel and especially to value the efforts of the employees to improve their professional performances. 


\section{References}

1. Antonio Carretta, Murray M. Dalziel e Alain Mitrani (2004)., Dalle risorse umane alle competenze, Metodi, Strumenti e casi in Europa per una gestione e sviluppo delle risorse umane basata su un modello comune di competenze, Editore Franco Angeli, p.148, Milano, Italia, 2004.

2. Arthur W.Sherman, Jr., George W. Bohlander şi Herbert J. Chruden (1998)., Managing Human Resourses, Sherman, Bohlander, Chruden, Eight Edition, Cap. X Employee motivation, p. 295, South-Western Publishing Co., Cincinnati, Ohio, SUA.

3. Diana Cawood (1991), Il manager assertivo, Come tratarea in modo piu efficace dipendenti, colleghi e superiori, Title originale Assertiviness for Managers, Learning Effective-Skills for Managing People, Self-Counsel Press, a Division of International Self-Counsel Press Ltd., Vancouver, Toronto Seattle, second edition, 1988, Editore Franco Angelli, p. 38, Milano, Italia.

4. Edward E. Lawler (1981), Pay and Organisation Development (Reading, Mass. Addison-Weslez, pp. 82-85.

5. Jason D. Shaw, Nina Gupta, and John. E. Delery (2002), Pay Dispersion and Workforce Performance: Moderating Effects of Incentives and Interdependence, ,, Strategic Management Journal p. 23.

6. John J. Gabarro (1991), Managing people and organizations, Harvard Business School Publications, Boston, Massachutetts, pp. 483-484, S.U.A.

7. John J. Gabarro (1992), Managing people and organizations, The practice of management series Harvard Business School, Cap. Managing performance appraisal work, Beer\&Walton, p. 199, S.U.A.

8. Lukacs Edit (2002), Evaluarea performantelor profesionale, Editura Economica, Bucuresti.

9. Robert Rodgers and John E. Hunter (1991) Impact of Management by Objectives on Organizational Productivity", Journal of Applied Psycology 76, p. 323-336.

10. Stefano Paneforte (1999), La gestione delle persone nell'impresa, Publishing CEDAM, p. 215, M. Armstrong, op.cit.

11. Encyclopedia of Management, Employee Job Evaluation, p. 253.

12. Information retrieved and processed by Courtyard Marriot Hotel, Italy and Iq Hotel, Romania. 